\title{
EL ABUSO DEL DERECHO: ENTRE LA MODERNIDAD Y LA POSMODERNIDAD
}

\section{Gunther Gonzales Barrón}

Doctor en Derecho por la Pontificia

Universidad Católica del Perú. Máster en Derecho

Constitucional por la Universidad de Castilla La

Mancha. Profesor ordinario de la Pontificia

Universidad Católica del Perú. Juez Superior

Titular de la Corte de Justicia de Lima

Email: info@gunthergonzalesb.com

SUMARIO: Introducción. 1. La modernidad en el Derecho: los Códigos liberales. 2. La posmodernidad en el Derecho: la protección de derechos fundamentales. 3. El abuso del derecho: entre la modernidad y la posmodernidad. 4. Construcción técnica del abuso de derecho. 5. Abuso del derecho de propiedad. 6. Abuso del derecho: principio constitucional. 7. Abuso de derecho: ¿límite intrínseco o extrínseco? 8. Conclusiones.

\section{RESUMEN:}

El abuso del derecho es una de esas nociones jurídicas de la que todos hablan, casi por intuición o sentido común, y la jurisprudencia no es la excepción, pues en su afán de sustentar una decisión presuntamente teñida de justicia puede utilizar una simple frase como toda motivación. Ese es el riesgo de los conceptos jurídicos generales, pero también su ventaja, pues la indeterminación permite que el juez pueda enfrentar problemas no regulados sin tener que remitirse al positivismo, pero salirse de esos estrechos límites requiere de una fuerte dosis argumentativa que justifique la sentencia en motivos de racionalidad práctica. El peligro de la generalidad se enmienda con la argumentación.

PALABRAS CLAVE: Abuso del Derecho, Propiedad, límites

\section{ABSTRACT:}

The abuse of law is one of those legal concepts from which all speak, almost by intuition or common sense, and jurisprudence is not the exception, in their desire to support a decision 
allegedly tainted justice can use a simple phrase like all motivation. That is the risk of general legal concepts, but also its advantage as the indeterminacy allows the judge to address issues not regulated without reference to positivism, but get out of those narrow limits requires a strong argument justifying the sentence dose on grounds of practical rationality. The danger of generality amendment argument.

KEYWORDS: Abuse of law, property, limits 


\section{LA MODERNIDAD EN EL DERECHO: LOS CÓDIGOS LIBERALES}

La modernidad se inaugura en el siglo XVII con Descartes y su fe en la razón del hombre como medio para conocer la verdad, alcanzar el conocimiento y lograr el progreso. Se plantea, así, una clara diferencia entre sujeto que conoce y el objeto de conocimiento. En tal perspectiva, el hombre es el amo y señor del universo que puede, a través de la razón, alcanzar todas las metas. Esta idea se conecta con la otra referida al progreso del hombre, que puede dominar sus impulsos, la técnica y la naturaleza.

El racionalismo origina una nueva forma de entender la ciencia, cuyas características son la observación, experimentación y causalidad. Por el contrario, la ciencia aristotélica, de fines, de trascendencias, de pura especulación, queda enterrada definitivamente ${ }^{1}$. Por ejemplo, la derrota de Galileo en el Tribunal de la Inquisición, en el siglo XVI, fue en realidad el anticipo del triunfo definitivo de la nueva ciencia.

El Derecho quedó influenciado rápidamente por esta nueva concepción filosófica de la vida y del mundo. El racionalismo jurídico nace con su fe en la razón del hombre para dotarse de reglas de convivencia, universales y eternas, por cuya virtud se vence el tiempo y el espacio, y si bien en un primer momento estas nuevas ideas se vincularon con el jus-naturalismo de carácter religioso, por su carácter de verdad absoluta, empero, pronto ambas corrientes terminaron distanciándose por el presupuesto dogmático que inspira la fe religiosa, lo que es incompatible con la razón. Precisamente, a partir del siglo XVII, surgen los representantes de esta nueva corriente, como Hugo Grocio ${ }^{2}$ y Samuel Puffendorf, así como el civilista Jean Domat; y en el XVIII, Robert Joseph Pothier.

${ }^{1}$ GOÑI, Carlos. Breve historia de la filosofía, Ediciones Palabra, Madrid 2010, p. 138, dice: "Se conoce por Racionalismo la corriente filosófica moderna inaugurada por Descartes, que abarca los siglos XVII y XVIII (momento en que se transforma en idealismo) y que tiene estas características generales:

- $\quad$ Confianza plena en la razón como único medio de explicar la realidad.

- Desconfianza en el conocimiento sensible y la experiencia.

- Creencia en la existencia de ideas innatas.

- Aplicación del método deductivo, teniendo como paradigma las matemáticas".

2 "Lo que hizo Grocio, en realidad, fue generalmente reconocido por los humanistas cuando redescubrieron a los estoicos. Sobre esta visión de conjunto fundó su tratamiento del derecho internacional como aquel al cual los soberanos deben sujetarse por la razón": FRIEDRICH, Carl Joachim. La Filosofía del Derecho, Fondo de Cultura Económica, México 1997, sin indicación de traductor, pp. 101-102. 
El Derecho romano, por ejemplo, es considerado un triunfo de la razón en el mundo antiguo, por lo que sus reglas son rescatadas para la modernidad, pero se elimina aquello que solo fue contingente o histórico, y que ya no tenía actualidad. Toda Europa fue romanizada precisamente en esa época, incluso las naciones que no tenían precedentes en tal sentido, como las germánicas o las del Norte. Por tanto, no es de extrañar que en el siglo XIX, Savigny escriba la monumental obra: "Sistema de derecho romano actual", con lo cual se conectaba el pasado y el presente, pero a través de un conjunto de reglas que se consideraban eternas ${ }^{3}$.

El racionalismo, además, toma como punto de partida el hombre, el individuo, su poder como ser racional. La famosa frase ergo cogito sum (pienso, luego existo) es una buena muestra del lugar central del hombre. En consecuencia, el Derecho de la modernidad otorga una fuerza irresistible a la voluntad como elemento fundacional de los derechos subjetivos, del Derecho objetivo y del propio Estado. En efecto, el contrato nace por efecto de la sola voluntad; la propiedad es el respeto a la voluntad del hombre sobre una cosa; la transferencia de dominioopera por la voluntad del propietario; la ley nace de la voluntad del Soberano o del Parlamento; y, finalmente, el Estado surge del contrato social, es decir, de la voluntad de los hombres.

El Derecho moderno es netamente individualista, voluntarista; y eso no es casualidad, pues se debe a las bases teóricas que lo justifican.

El individualismo se relaciona con el capitalismo económico, cuya idea subyacente es, precisamente, confiar en la voluntad del hombre, en su libertad, en sus decisiones particulares que sumadas en el interior de la sociedad llevan a la prosperidad general. Por el contrario, el Estado se considera anti-natural, una organización corporativista que solo puede sustentarse por necesidad, en cuanto se le requiere para garantizar la libertad. En tal sentido, cada persona decide qué producir, en qué invertir, cuánto pagar y con quién contratar. El mercado es una suma de individualidades que actúan en su propio beneficio, lo que conlleva un beneficio

\footnotetext{
${ }^{3}$ Este es uno de los puntos débiles de la teoría de Savigny, pues si el Derecho nace del espíritu del pueblo, lo que por definición es irracional, sin embargo, no se entiende la búsqueda de un derecho romano depurado, que supera el tiempo por su racionalidad intrínseca, y que proviene de un pueblo desaparecido.
} 
colectivo. De esta forma, se logrará la "riqueza de las naciones" (Adam Smith), la prosperidad y el progreso.

Sin embargo, el libre desarrollo de las fuerzas productivas necesita un Derecho instrumental para sus fines, que asegure la propiedad privada y las inversiones, que dote de instrumentos legales a la iniciativa privada y que respete los contratos. Sin embargo, no basta el individualismo como trasfondo de las normas, pues se requiere seguridad jurídica; y, para ello, se hace imprescindible un cuerpo legal que condense todo el derecho de la propiedad, de los contratos y la herencia. En ese texto jurídico, casi sagrado, se encontrará la solución de todos los problemas con una simple consulta. La codificación, por tanto, se convierte en la técnica legislativa propia de la modernidad, pues aspira a contener normas que son universales (todos los hombres son iguales, por lo que no hay diferencias corporativas), completas (todas las soluciones se encuentran en el código, y las normas anteriores quedan derogadas), coherentes (orden racional de las normas) y seguras (normas técnicamente bien redactadas, por escrito -se descarta los usos-, públicas, no retroactivas).

Por su parte, si la ley prevé todas las hipótesis en un cuerpo legal completo, entonces el juez se convierte en un autómata que subsume hechos en las normas, por lo cual se limita a reconocer soluciones que ya están previstas en la ley. En caso de lagunas, el juez deberá aplicar la analogía, es decir, se servirá de las propias normas codificadas. En el momento de mayor extremismo se establece que los vacíos legales deban colmarse por el propio Parlamento mediante recursos dirigidos a tal instancia. En este contexto, los jueces no pasan de ser funcionarios burocratizados que realizan un trabajo rutinario consistente en repetir las normas en la solución de casos concretos.

En buena cuenta, el Derecho moderno es individualista en extremo; respetuoso de la voluntad, aunque sea para engañar o envilecer; asegurador de las libertades de contratación y de dominio, aunque los hombres sean desiguales de facto; y encerrado en Códigos completos e inmutables, que rápidamente quedan desfasados y superados por las nuevas condiciones sociales y económicas.

Los Códigos dotan a los individuos de libertad de comercio e industria (eliminación de los antiguos gremios), libertad de intercambios (autonomía de la voluntad) y libertad de propiedad (dominio sin límites). No obstante, la centralidad del sistema se encuentra en la 
protección de los propietarios, quienes en ejercicio de tal derecho, podrán intercambiar, comerciar o producir libremente en ese nuevo orden económico. Por tanto, los Códigos liberales son el instrumento jurídico para asegurar la propiedad.

Por supuesto que la libertad económica no va aparejada de libertad política, pues las nuevas leyes se dictan en sociedades profundamente oligárquicas, anti-democráticas y sin atribución general de ciudadanía ${ }^{4}$.

\section{LA POSMODERNIDAD EN EL DERECHO: LA PROTECCIÓN DE DERECHOS FUNDAMENTALES}

La postmodernidad nace en las últimas décadas del siglo XX como reacción frente a los problemas del hombre que no se han solucionado por la racionalidad. En efecto, los avances del conocimiento, de la técnica y de la ciencia, que tanto han contribuido al crecimiento de la riqueza, al desarrollo tecnológico, a las inmensas fortunas, a la globalización, sin embargo, no ha logrado la felicidad privada, amenazada por el consumismo y la angustia; ni la honestidad pública, aquejada por la corrupción; ni la libertad política, sojuzgada por las fallas notorias de la democracia; ni tampoco se ha logrado la igualdad entre los hombres, socavada por las diferencias entre la clase dominante, que sigue siendo minúscula frente a la masa de desposeídos, pues la pobreza se mantiene frente a una escandalosa riqueza.

La época presente marca el punto de mayor prosperidad en la historia del hombre, de mayor conocimiento, el de la sociedad global por la rapidez de las comunicaciones; pero al mismo tiempo representa el momento de las guerras más sangrientas, de los totalitarismos más feroces, de las mayores perversiones, del ocaso espiritual y moral. Estas contradicciones, tan marcadas, hacen que el hombre dude y abandone el proyecto del modernismo; por tanto, queda de lado la idea del progreso imparable, de la unificación de las diferentes sociedades bajo parámetros y éticas comunes, o la absorción de los países satélites por la fuerza expansiva del mundo occidental.

\footnotetext{
${ }^{4}$ Los países que sancionan códigos no conceden ciudadanía política a todos los hombres, sino a los que tributan al erario público, lo que fundamentalmente ocurría con los propietarios de predios, que era la mayor fortuna de la época. No obstante, a todos se les concedían ciudadanía civil, pues formalmente regía el principio de libertad e igualdad -banderas de la revolución francesa-.
} 
En buena cuenta, los ideales de la modernidad no se han cumplido. La unidad social se disuelve en las minorías, cada vez más importantes y con agenda propia; la ética de las naciones occidentales ya no es la única que se tiene en cuenta, y, por el contrario, se critica hoy la falta de los mismos valores que permitieron la construcción de esas sociedades; la transparencia e información de los medios, que si bien transmiten los hechos en tiempo real, empero, se desvanece con la banalización de los contenidos, con la multiplicidad de versiones; y, por último, la realidad, única y objetiva, parece no existir, y solo quedan los subjetivismos.

La idea clave del progreso incesante e imparable, dominado por la razón, no se ha concretado. En cambio, se constata que la historia no es una línea ideal que avanza desde el primitivismo hasta la conciencia absoluta, sino, más bien, es el conjunto de historias diversas, no ensambladas, ni lineales. La supuesta historia del progreso no es otra que la contada por los vencedores occidentales, ideologizada, reducida a grandes sucesos que importan a las clases dominantes; es claro, pues, que los vencidos no forman parte de la historia ${ }^{5}$.

La postmodernidad plantea "de-construir" el edificio conceptual de la razón, en palabra de Jacques Derrida. Si antes había totalitarismo de la ética, en el presente hay relativismo; si antes había mundo occidental dirigente, en el presente hay muchos mundos; si antes había historia lineal, en el presente hay multitud de historias que no conducen necesariamente al progreso; si antes había la pretendida seguridad para la vida, en el presente hay debate, diálogo problemático, difícil consenso.

El Derecho no ha sido inmune a la postmodernidad.

\footnotetext{
5 “Pues bien, en la hipótesis que yo propongo, la modernidad deja de existir cuando -por múltiples razonesdesaparece la posibilidad de seguir hablando de la historia como una entidad unitaria. Tal concepción de la historia, en efecto, implicaba la existencia de un centro alrededor del cual se reúnen y ordenan los acontecimientos (...) La crisis de la idea de la historia lleva consigo la crisis de la idea de progreso: si no hay un decurso unitario de las vicisitudes humanas, no se podrá ni siquiera sostener que avanzan hacia un fin, que realizan un plan racional de mejora, de educación, de emancipación. Por lo demás, el fin que la modernidad pensaba que dirigía el curso de los acontecimientos era también una representación proyectada desde el punto de vista de un cierto ideal del hombre": VATTIMO, Gianni. "Posmodernidad: ¿una sociedad transparente?", en VV.AA. En torno a la posmodernidad, Anthropos Editorial, Barcelona 2011, pp. 10-11.
} 
El cuestionamiento de la racionalidad conlleva que suceda lo propio con los conceptos jurídicos basados en ella, tales como la codificación, el positivismo, el individualismo, la libertad absoluta, la solución única y correcta en las controversias jurídicas, la seguridad jurídica como valor prevaleciente.

Por tanto, el nuevo modo de ser del Derecho se construye sobre la base de los derechos humanos, que son valores de alto contenido ético, pero que sufren de gran indeterminación. En tal contexto, la codificación, el normativismo y la seguridad jurídica liberal pierden sentido. También sufren las ideas de soberanía y democracia parlamentaria como medios para construir la voluntad estatal, pues, hoy, tales absolutos se derrumban frente a las Constituciones, los tratados de derechos humanos o los tribunales internacionales.

Asimismo, la postmodernidad reconoce las diferencias, las minorías, los "otros", que también son incluidos en un proyecto conjunto, pero no común. La tolerancia pasa a convertirse en valor fundamental; pero ello también trae preocupación por los pobres y los marginados. Los derechos humanos no solo son libertades frente al Estado, sino también prestaciones con la meta de una igualdad sustancial y real, por tanto, el individualismo cede su lugar a la solidaridad.

La postmodernidad derrumba las bases teóricas del Derecho civil liberal.

La codificación es, precisamente, una técnica legislativa nacida durante el liberalismo, que se caracteriza por regular la vida social con pretensión de integridad, claridad, orden y sistematicidad; por tanto, cualquier conflicto jurídico puede resolverse mediante la simple consulta de ese libro sagrado, en el cual se deberían encontrar todas las respuestas a los problemas jurídicos. Los Códigos se basan en las ideas de generalidad (medio) y seguridad jurídica (fin); pero su trasfondo filosófico no es otro que el positivismo y el formalismo. En efecto, todo se resuelve con la ley en la mano, y no existe nada más que buscar.

El neo-constitucionalismo, los derechos humanos y las modernas concepciones filosóficas del derecho han producido el estallido de la codificación, pues al superarse el positivismo que se concentra en normas simples cuyo fin es la certeza, entonces produce el fenómeno denominado de "indeterminación del derecho", por lo que hoy no se sabe a ciencia cierta cuál será la solución de alguno de los llamados “casos difíciles", pues no solo entra en juego una 
norma del Código, sino también uno o más principios elásticos contenidos en la Constitución, una norma internacional de derechos humanos, la jurisprudencia de un Alto Tribunal o Corte, o incluso el informe de un relator temático del sistema universal de derechos humanos. A ello se suma que el juez no es más la boca de la ley, sinoel centro del sistema jurídico como último garante de los derechos fundamentales del hombre. La falta de certeza es una consecuencia directa de la aplicación de los derechos fundamentales en la solución de los conflictos civiles ${ }^{6}$.

Las fuentes del derecho se han expandido verticalmente (más normas y más decisiones jurisprudenciales; algunas de las veces superpuestas entre sí), pero también en sentido horizontal (el contenido de cada norma legal, que debe adecuarse a la Constitución o a un tratado de derechos humanos interpretado por una Corte Internacional, se ha vuelto indeterminado). Así pues, en el Estado Constitucional los casos jurídicos se vuelven complejos, pues en múltiples oportunidades se resuelven por virtud de principios jurídicos que requieren de la técnica de ponderación para dilucidar el conflicto entre derechos fundamentales; y ya no por la simple aplicación mecánica de reglas técnicas establecidas en un Código. El Derecho actuado por medio de principios abiertos y de difícil concreción, y no por reglas exactas y de aplicación incondicionada, es la negación misma del espíritu que animó en su momento el fenómeno de la codificación. Por tanto, no es que los Códigos estén en problemas o desfasados con relación a la tecnología moderna o a la nueva sociedad, sino que la idea misma de un código es la que se encuentra en profunda crisis, y por ahora parece ser una idea en declive, y tal vez ya superada.

El Derecho se ha vuelto más complejo, y eso no cuadra con la concepción de reglas claras y sencillas que anima a los Códigos ${ }^{7}$. Es más, hoy se dice que todos los principios son

\footnotetext{
6 "Al derecho privado, que hasta ahora determinaba en solitario la configuración de las relaciones jurídicas y la decisión de los conflictos jurídicos, se le sobrepone otro orden jurídico; este tiene incluso primacía sobre él, si bien consiste solo en principios jurídicos, además de escasos, muy amplios y frecuentemente indeterminados, cuyo significado para el caso concreto siempre será de más difícil determinación que el correspondiente a las normas pertinentes del Derecho privado: la claridad y la certeza jurídica, necesarias justamente para el tráfico jurídico-privado, resultan afectadas de modo no irrelevante. La falta de claridad se incrementa por la peculiaridad de la constelación de los derechos fundamentales": HESSE, Konrad. Derecho Constitucional y Derecho Privado, Editorial Civitas, Madrid 2001, traducción de Ignacio Gutiérrez, pp. 59-60.
}

7 "Resulta aquí oportuna la contraposición, cuyo profundo significado originario ya no se percibe hoy, entre scientia iurisyiuris prudentia, la primera como racionalidad formal, la segunda como racionalidad material, es decir, orientada a los contenidos. (...) Mientras el criterio que preside las primeras es la oposición cualitativa verdadero - falso, todo o nada, el 
derrotables, es decir, ellos mismos entran en conflicto, precisamente por su natural indeterminación, y en consecuencia, en el caso concreto debe dilucidarse qué principio prevalece; sin embargo, esa preferencia no puede generalizarse ni de ella establecerse una regla abstracta, por cuanto solo sirve para resolver una determinada circunstancia fáctica. En suma, las decisiones jurídicas por principios tienen la ventaja de adecuarse a la verdadera naturaleza del Derecho, no solo reducido a normas, con entrada de la moralidad e importancia de la argumentación, pero tiene el inconveniente de la mayor incertidumbre respecto de la solución del caso. En estas circunstancias, la codificación puede considerarse, hoy por hoy, una técnica legislativa incompatible con el actual modo de ser del Derecho.

Si todos los principios del derecho son derrotables, entonces las reglas claras, precisas y delimitadas no pasan de ser una ilusión; pues hasta las normas más importantes del sistema pueden decaer en un caso concreto; con mayor razón las reglas quedan desplazadas cuando se enfrentan con los principios. Por tal motivo, las cláusulas generales de los Códigos, tales como la buena fe o la prohibición del abuso del derecho, cada día ganan más importancia para superar el formalismo, conceptualismo y economicismo ${ }^{8}$.

que preside las segundas es una progresión cuantitativa que va desde lo menos a lo más apropiado, desde lo menos a lo más oportuno, desde lo menos a lo más adecuado y productivo. Son dos mentalidades contrapuestas en general. En el lenguaje que hoy suele usarse, esta atención a lo posible en la realización de los principios se denomina "razonabilidad": una discutible expresión para aludir a lo que clásicamente se conocía como la "prudencia" en el tratamiento del derecho.Está claro que este modo de situarse frente al derecho constituye solamente una actitud, una predisposición hacia soluciones dúctiles que tomen en consideración todas las razones que puedan reivindicar buenos principios en su favor. No es, en cambio, la "clave" para resolver todo problema jurídico, como si se tratase de una fórmula que permitiera obtener la solución de un problema matemático. Busca la respuesta más adecuada para las expectativas legítimas $\mathrm{y}$, por ello, está abierto al enfrentamiento entre todas las posiciones que remiten a principios vigentes en el derecho. En los contextos pluralistas es necesario hacer "discursivo" y "persuasivo" el procedimiento a fin de alcanzar el punto de máxima realización de los principios en juego": ZAGREBELSKY, Gustavo. El Derecho dúctil. Ley, derechos, justicia, Editorial Trotta, Madrid 2009, traducción de Marina Gascón, p. 123.

${ }^{8}$ Por tal motivo, discrepo de la opinión del buen amigo LEÓN, Leysser.El sentido de la codificación civil, Palestra Editores, Lima 2004, p. 304: "En la reforma del Código Civil que se está preparando se debería reducir al mínimo el empleo de las cláusulas normativas generales, y preferir a ellas, una regulación detallada y puntual de figuras que han brillado por su ausencia en la jurisprudencia de los últimos veinte años". Esta propuesta implica regresar, sin más, al positivismo. 
Pero, nótese que estamos hablando de una crisis de la técnica legislativa, pero no de una crisis de los derechos de la persona. Los Códigos pierden importancia, pero no el Derecho Civil, solo que este se redimensiona con la perspectiva de una justicia que se pretende lograr a través de los valores que emanan de la Constitución y del sistema internacional de derechos humanos, lo que en el actual estado de nuestra civilización constituye, y todo indica que es así, un paso adelante sobre el cual no podrá volverse ${ }^{9}$.

El nuevo sistema jurídico, basado en los derechos humanos, simplemente es incompatible con los Códigos de reglas simples que pretendían conseguir certeza y seguridad.

En buena cuenta, una mayor preocupación por la justicia conlleva necesariamente una dosis creciente de incertidumbre, pues entran a tallar los principios, la argumentación, las distintas fuentes normativas, lo que produce inseguridad en la solución. Ya no se admite que una regla específica pueda responder a cada problema jurídico, sin mayor debate o carga argumentativa. En suma: a más justicia, menos seguridad; a más seguridad, menos justicia. El neoconstitucionalismo actual opta por lo primero; el positivismo optó decididamente por lo segundo.

\section{EL ABUSO DEL DERECHO: ENTRE LA MODERNIDAD Y LA POSMODERNIDAD}

${ }^{9}$ En Europa se discute actualmente si el Derecho Privado se encuentra sujeto a una relación de subordinación o complementariedad respecto de los derechos fundamentales de la persona. Por la subordinación se entiende que las relaciones entre individuos no se rigen sustancialmente por el Derecho privado, sino por los derechos fundamentales consagrados en las Constituciones o Tratados de derechos humanos. Aquí el Derecho privado no solo es interpretado a la luz de los derechos fundamentales, sino que su normativa es sustituida en sectores importantes. Por el contrario, la complementariedad implica que el Derecho privado no pierde su capacidad de regular las relaciones entre particulares de acuerdo a su propia lógica, conservando su autonomía. Aquí los derechos fundamentales influyen, pero difícilmente sustituyen las normas privadas: CHEREDNYCHNKO, Olha. "Derechos Fundamentales y Derecho Privado. ¿una relación de subordinación o complementariedad?”, en Palestra del Tribunal Constitucional. Revista de doctrina y jurisprudencia, Palestra Editores, $\mathrm{N}^{\circ}$ 1, Lima, enero 2008, pp. 106-107. En nuestra opinión, la complementariedad presupone que las reglas de los Códigos hacen efectivos los derechos fundamentales, por lo que se trata de una visión más cercana al liberalismo; en cambio, la subordinación es propia del Estado Social en donde el centro lo constituye el hombre, su dignidad, la igualación material entre seres humanos, la dotación de un mínimo existencial, y todo eso exige que los Códigos sean re-leídos y re-interpretados. 
El abuso del derecho es una figura jurídica de clara inspiración social, pero nace en el siglo XIX, en pleno auge de los Códigos liberales, por lo que surge como una lógica reacción frente al individualismo. En efecto, el Código francés de 1804 es el paradigma de tutela del propietario absolutista, exclusivo y prácticamente incondicional, cuyo derecho se encuentra configurado por la ley, y fuera de ello no hay nada más que buscar o cuestionar, sin embargo, esta visión exagerada y extremista no podía mantenerse. "La figura del abuso del derecho surgió en la jurisprudencia francesa para corregir dos rasgos jurídico-culturales del Código de Napoleón, el formalismo legal y el absolutismo de los derechos, y de manera particular el de propiedad" ${ }^{\prime 10}$. Por tanto, el surgimiento del abuso del derecho, durante la modernidad decimonónica, no es una paradoja, sino la natural reacción frente al extremismo individualista que originaba resultados inaceptables en relación con el valor de justicia material.

En tal sentido, la famosa sentencia de la Corte de Colmar de 02 de mayo de 1855, tantas veces citada, se refiere a un propietario que edificó sobre su casa una chimenea inútil delante de la ventana de su vecino con la sola intención de perjudicarlo privándole de la luz. Allí se dijo que el derecho de propiedad "debe tener por límite la satisfacción de un interés serio y legítimo". Un año después el Tribunal de Lyon sancionó a un propietario que instaló una bomba de agua en el subsuelo para succionar el agua de una fuente para el solo perjuicio a su vecino, pues el agua recolectada se conducía directamente al río. El propietario fue condenado, según palabras del Tribunal, pues había utilizado "el poder de abusar de su cosa inspirado exclusivamente por el ánimo de dañar”. Luego el Tribunal de Compiègne, mediante sentencia de 19 de febrero de 1913, sancionó que el titular no puede ejercer su derecho "para un fin distinto de aquel para el que le ha sido reconocido por el legislador"11.

Por su parte, el Código Alemán consagró el abuso del derecho en una norma de carácter restrictivo, fundada en el elemento subjetivo (dolo), como se aprecia del parágrafo 226 BGB: "Prohibición del abuso.- El ejercicio de un derecho es ilícito si solo puede tener por finalidad causar daño a otro"12.

\footnotetext{
${ }^{10}$ RENGIFO GARCÍA, Ernesto. Del abuso del derecho al abuso de la posición dominante, Universidad Externado de Colombia, Bogotá 2004, p. 45.

${ }^{11}$ Ibíd., pp. $45-46$.

${ }^{12}$ La presente traducción y de las otras normas del Código Civil Alemán se toman de: LAMARCA MARQUÉS, Albert (Dir. de la traducción). Código Civil Alemán y Ley de Introducción al Código Civil, Marcial Pons, Madrid 2008.
} 
Para la modernidad, en el mejor de los casos, el abuso del derecho es una curiosidad propia de académicos inoportunos ${ }^{13}$; o en el peor, una grave distorsión que permite la indebida discrecionalidad de los jueces, lo que pone en peligro el supuesto dogma de la actividad judicial como boca de la ley, cuyo método se reducía a la simple subsunción. No obstante, el abuso del derecho es el primer paso que llevará finalmente a desmontar el individualismo absoluto; es la cuña por la que se filtra el nuevo paradigma. Si bien es cierto que esta teoría por sí sola no produjo modificaciones dramáticas en la concepción tradicional del Derecho civil $^{14}$, empero, tuvo el mérito de ser pionera en un contexto jurídico hostil, que miraba con desconfianza las perspectivas sociales, pues a partir de los mediados del XIX se temía el creciente influjo de las ideas marxistas, y cuyo recelo se acentuaba por la pretensión de mediatizar los derechos individuales absolutos, como la propiedad, con el fin de dar entrada al impredecible criterio judicial, basado en subjetividades, y no en normas claras y expresas.

\section{El abuso del derecho, por tanto, pone en entredicho dos ideas básicas de la modernidad:}

el individualismo, atacado por la solidaridad, y la seguridad normativa de la codificación, reemplazada por conceptos generales susceptibles de interpretación judicial.Por tanto, es evidente que la visión conceptualista del Derecho es incompatible con su nuevo modo de ser: dinámico, argumentativo, anti-formalista, valorativo y de protagonismo de lo jurisdiccional frente a la ley ${ }^{15}$.

En tal sentido, la doctrina francesa considera que los antiguos derechos absolutos se relativizan, pues su ejercicio se realiza en el contexto social, no en el vacío, por lo que todo derecho tiene una misión social, un motivo legítimo. "Por ejemplo, no podrían ser puestos en ningún caso al servicio de la malicia, de la mala fe, de la voluntad de perjudicar al prójimo; no pueden servir para realizar la injusticia; no deben nunca ser apartados de su vía regular; de

\footnotetext{
${ }^{13}$ Las tesis negativas lo califican como institución contradictoria, pues el abuso del derecho es no-derecho, por tanto nunca podría presentarse un derecho susceptible de abuso. En tal sentido lo da cuenta: MENEZES CORDEIRO, António Manuel da Rocha. Da Boa Fé no Direito Civil, EdicõesAlmedina, Coimbra 2013, pp. 679-682.

${ }^{14}$ La doctrina considera que el abuso del derecho constituye un "avance tímido": Ibíd., p. 684.

${ }^{15}$ El profesor Gustavo Ordoqui se expresa en los siguientes términos respecto a la decadencia del positivismo: "Este enfoque, en definitiva, ratifica los errores y exageraciones de aquellos que entienden que todo está en respetar solamente el texto de la ley y, por error, solo en esta ponen toda su confianza y esperanza".
} 
hacerlo así, sus titulares no lo ejercitarían verdaderamente, un abuso de derechos de que serían responsables con relación a las víctimas posibles"16.

Por su parte, la doctrina alemana fundó el abuso del derecho en la vieja exceptiodoli del Derecho romanoo en la prohibición del dolo. En todo caso, era una teoría "extraña a la pandectística"17. Incluso, los autores alemanes contemporáneos consideran que el par. 226 BGB es "poco significativo o inútil" ${ }^{18}$.No obstante, se ha construido una especie de teoría de la prohibición del ejercicio inadmisible de $\operatorname{los}$ derechos ${ }^{19}$, con recurso a la cláusula de las buenas costumbres del par. $826^{20}$ o de la buena fe del par. $242^{21}$, como una fórmula para superar la estrechez dogmática.

\section{CONSTRUCCIÓN TÉCNICA DEL ABUSO DE DERECHO}

La jurisprudencia sobre abuso del derecho revela diversas hipótesis en las cuales el titular de un derecho actúa formalmente dentro las prerrogativas establecidas porla ley, empero el resultado es de manifiesta injusticia, pues choca frontalmente con un valor reconocido por el ordenamiento jurídico. Es el caso típico del propietario que mandó construir una falsa chimenea sin utilidad alguna para sí, pero con el fin de perjudicar la vista del vecino.

${ }^{16}$ JOSSERAND, Louis. Derecho Civil, EJEA - Bosch y Cía Editores, traducción de Santiago Cunchillos y Manterola, T. I, V. I, p. 154.

${ }^{17}$ MENEZES CORDEIRO, Da Boa Fé no Direito Civil, Op. Cit., p. 687.

18 Ibíd., p. 691.

Es significativo que el monumental tratado de ENNECCERUS, Ludwig, KIPP, Theodor y WOLFF, Martin. Tratado de Derecho Civil, traducción de José Alguer y Blas Pérez González, T. III-1으, p. 337, le dedique pocas líneas al tema y, además, sin profundidad.

${ }^{19}$ MENEZES CORDEIRO, Da Boa Fé no Direito Civil, Op. Cit., pp. 693-695.

${ }^{20}$ Par. 826 BGB: “Daño doloso contrario a las buenas costumbres.- Quien de una forma que contraviene las buenas costumbres causa dolosamente un daño a otro está obligado frente a este al resarcimiento del daño".

${ }^{21}$ Par. 242 BGB: "Prestación de buena fe.- El deudor está obligado a cumplir la prestación según las exigencias de la buena fe conforme a los usos del tráfico". 
En tal contexto, los filósofos del derecho han realizado una construcción teórica de innegable precisión: "las acciones abusivas son acciones prima facie permitidas pero que finalmente resultan, considerando todas las cosas, prohibidas" ${ }^{22}$. La prohibición surge como: "supuestos de laguna axiológica en el nivel de las reglas: se trata de casos que las reglas del sistema solucionan permisivamente, pero sin tomar como relevante para esa solución alguna propiedad que, de acuerdo con la hipótesis de relevancia que se derivan de los principios, sí debiera tomarse en cuenta como relevante para solucionar prohibitivamente el caso"23.

Por su parte, un profundo estudio dogmático del Derecho portugués concluye, en el mismo sentido, que el abuso del derecho reside en la disfuncionalidad de los comportamientos que si bien permitidos por normas jurídicas, empero no se corresponden en el sistema en el que aquellas se integran ${ }^{24}$.

En efecto, la regla jurídica permite la conducta (por ejemplo, art. 923 del Código Civil: la propiedad comprende la facultad de disfrute de las cosas), pero por efecto de la coherencia valorativa del sistema jurídico esa conducta no es aceptable a la luz de un principio jurídico (por ejemplo: prohibición de dolo, actuación de buena fe, venire contra factum proprium, etc.). La consecuencia es que la conducta, formalmente permitida por la regla, empero se convierte en prohibida por aplicación del principio, por tanto, la coherencia del sistema exige que la laguna axiológica deba ser completada por la nueva regla prohibitiva, que surge del principio, y que normalmente tiene origen jurisprudencial.

El principio afectado con la conducta abusiva no solo puede tener carácter subjetivo, como la interdicción del dolo o del fraude, sino también objetivo, al margen de la intención del infractor $^{25}$, por lo que "se constituye como una conducta contraria a la función social-

\footnotetext{
${ }^{22}$ ATIENZA, Manuel y RUIZ MANERO, Juan. Ilícitos atípicos, Editorial Trotta, Madrid 2006, pp. 58-59.

${ }^{23}$ Ibíd., p. 62.

${ }^{24}$ MENEZES CORDEIRO, Da Boa Fé no Direito Civil, Op. Cit., p. 882.

25 “Los límites intrínsecos derivan de la propia naturaleza de cada derecho y de su función social. Dentro de ellos suelen diferenciarse a su vez los límites objetivos (que se desprenden de la propia naturaleza, de la misma realidad del derecho) de los subjetivos (que derivan de la actitud del sujeto titular y de la forma de realizar el propio derecho). (...) La infracción del límite objetivo intrínseco nos sitúa por lo general ante un fraude de ley, mientras que la vulneración de un límite subjetivo intrínseco nos coloca ante un abuso del derecho": FERNÁNDEZ SEGADO, Francisco. "Dogmática de los derechos de la persona en la Constitución Española de 1978 y en su interpretación por el Tribunal Constitucional", en Derecho. Revista de la Facultad de Derecho de la
} 
económica inherente a cada derecho subjetivo"26, que también puede implicar "transgresión del principio de la buena fe, de la moral o de las buenas costumbres" ${ }^{27}$. En buena cuenta, las posiciones jurídicas se deben ejercer en consonancia con su finalidad (ratio essendi), dentro de un ejercicio responsable, en atención a su función social, y conforme la buena fe objetiva ${ }^{28}$.

El tránsito de la permitido a lo prohibido conlleva que la conducta sea calificada como "ilícito atípico", pues la solución del caso concreto no está prevista en una regla, por lo que la laguna "obedece a una necesidad de coherencia (de coherencia valorativa o justificativa) del sistema jurídico: se trata de que se produzca un ajuste entre la dimensión directiva y la justificativa del Derecho, entre las reglas y los principios. En algunos sistemas (los de civil law o de Derecho continental) eso se logra, por un lado, recurriendo a la analogía y, por otro, mediante las figuras del abuso del derecho, el fraude a la ley y la desviación de poder"29.

La conducta abusiva, como acto ilícito, puede originar daño resarcible (art. 1969 CC), pero no siempre $^{30}$, pues bien puede ocurrir que la tutela del principio afectado requiera de remedios diferentes: levantamientodel velo de una persona jurídica, convalidación de la nulidad, inhibición de la conducta infractora para el futuro, etc., es decir, la existencia de daño no es requisito imprescindible para la configuración del abuso del derecho, sin perjuicio de reconocer que es la consecuencia más frecuente. "El abuso del derecho no se reduce a la

Pontificia Universidad Católica del Perú, N 48, Lima 1994, pp. 239-240. La visión general del profesor español es correcta, en cuanto reconoce que existen límites intrínsecos del derecho, tanto objetivos (disfuncionalidad), como subjetivos (dolo), pero se equivoca en cuanto considera que la infracción al límite objetivo lleva al "fraude", pues por definición la conducta fraudulenta es dolosa, por tanto subjetiva, y no objetiva; en consecuencia, el abuso del derecho se presenta en ambas hipótesis (objetiva/subjetiva) siempre que la conducta se encuentre amparada en una regla de derecho, pero proscrita por un principio.

${ }^{26}$ FERNÁNDEZ SESSAREGO. Carlos. "Abuso del derecho (art. 103 Constitución)”, en GUTIÉRREZ, Walter (Dir.). La Constitución Comentada, 2o edición, Gaceta Jurídica, Lima 2013, Tomo II, p. 704.

${ }^{27}$ Ibídem. El profesor Gustavo Ordoqui señala que: "la buena fe como principio general del Derecho cumple también en nuestro sistema jurídico la función de control al ejercicio de los derechos subjetivos"

${ }^{28}$ RODOVALHO, Thiago. Abuso de derecho y derechos subjetivos, ARA Editores, Lima 2014, traducción de Juan Carlos Panez Solórzano y César Edwin Moreno More, p. 227.

${ }^{29}$ ATIENZA, Manuel y RUIZ MANERO, Juan. Ilícitos atípicos, Op. Cit., p. 126.

30 Por el contrario, un importante sector, del cual no se exoneran los filósofos (Ibíd., p. 57), considera erróneamente que el daño es elemento constitutivo del abuso del derecho. 
responsabilidad civil y tampoco se confunde con ella" ${ }^{, 31}$, por lo que las consecuencias del acto abusivo son de diversa índole, "como tutelas inhibitorias, supresión del ejercicio de la posición jurídica (supressio), surgimiento de derechos (surrectio), nulidad de cláusulas, litigio de mala fe, etc. ${ }^{, 32}$.

El art. II del título preliminar del Código Civil Peruano señala que: "La ley no ampara el ejercicio ni la omisión abusivos de un derecho. Al demandar indemnización u otra pretensión, el interesado puede solicitar las medidas cautelares apropiadas para evitar o suprimir provisionalmente el abuso" ${ }^{33}$, por lo cual nuestro ordenamiento establece que el abuso del derecho puede dar lugar a cualquier pretensión destinada a remover la conducta abusiva, y no solo la indemnizatoria ${ }^{34}$.

En resumen, "puede decirse que la categoría de los ilícitos atípicos -lo que incluye el abuso del derecho- es común a todos los ordenamientos jurídicos evolucionados, puesto que resulta necesaria para evitar el formalismo extremo en la aplicación del Derecho, que conduciría a la incoherencia valorativa de las decisiones jurídicas ${ }^{\text {} 35}$.

\section{ABUSO DEL DERECHO DE PROPIEDAD}

\footnotetext{
${ }^{31}$ RODOVALHO, Thiago. Abuso de derecho y derechos subjetivos, Op. Cit., p. 226.

${ }^{32}$ Ibídem.
}

${ }^{33}$ La teoría del abuso del derecho se consagró en el Código Civil alemán y en el Código Civil suizo (Art. 2, num. 2: "el manifiesto abuso de un derecho no está protegido jurídicamente"), pasando de allí a nuestro Código de 1936 y luego al vigente Código de 1984.

34 “El artículo II del Título Preliminar del Código Civil vigente introdujo en su versión primigenia una importante innovación como es la de establecer la posibilidad de accionar para evitar que se produzca un acto abusivo o para suprimir aquel en curso. En este sentido, el numeral autorizaba al interesado a solicitar se adopten las medidas que fueren necesarias para impedir la realización de un acto que estaría destinado a lesionar sus intereses (...). Estimamos un acierto, que constituye un valioso precedente en la legislación comparada, que el Código Civil de 1984 prescribiese en su versión original la tutela preventiva de los intereses que pudieran verse afectados con una posible acción abusiva, así como el que se permitiese también la supresión del abuso en acto": FERNÁNDEZ SESSAREGO, Carlos. El Abuso del Derecho, Editora Grijley, Lima 1999, pp. 281-282. La misma postura se mantiene con la nueva redacción del art. Il del Título Preliminar en virtud de la modificación de 1992 por obra de las disposiciones finales del Código Procesal Civil, aprobado por el Decreto Legislativo $\mathrm{N}^{\circ} 768$.

${ }^{35}$ ATIENZA, Manuel y RUIZ MANERO, Juan. Ilícitos atípicos, Op. Cit., p. 126. 
El ponente del libro V del Código Civil de 1984, sobre derechos reales, admite la potestad de los jueces para decidir si el propietario ha violado la "obligación" de armonizar su derecho con el interés social (o con el bien común, según el art. 70 Const.). Para llegar a esta afirmación se emparenta la "violación al interés social" como un caso de abuso del derecho (art. $924 \mathrm{CC})^{36}$, y, en consecuencia, queda habilitada la tutela inhibitoria y/o resarcitoria a favor del perjudicado, según fuera el caso.

En efecto, una de las vías para corregir las disfuncionalidades en el ejercicio de un derecho es la técnica del abuso del derecho ${ }^{37}$, con lo cual, se declaran ilícitas ciertas conductas a pesar de su falta de tipificación en reglas, pero que se deducen de la vigencia de los principios. Estos actos son ilícitos per se, por lo tanto, escapan del ámbito propio del derecho subjetivo, en este caso, de la propiedad ${ }^{38}$.

La teoría del abuso del derecho se construye sobre la base de ejercicios anormales, exóticos o dolosos del propietario, conforme se aprecia del repertorio jurisprudencial, cuyo caso típico es el francés del siglo XIX, en el cual se puso límites al derecho de propiedad cuando este se ejercitaba con la sola intención de perjudicar a otro. Se cita el famoso caso del Tribunal de Colmar en 1855, por el cual se evitó que un propietario levantara una falsa chimenea frente a la ventana de un vecino, sin más finalidad que la de incomodarle; de la misma forma un Tribunal de Lyon de 1856 sancionó el hecho de vaciar continuamente el agua de un pozo solo

36 “Una crítica que se hizo con referencia al art. 34 de la Constitución antigua (de 1933) es que no contenía una sanción. Es decir, se limitaba a establecer un precepto de carácter declarativo al disponer que el ejercicio de la propiedad debía armonizar con el interés social. Pero no decía que ocurría en caso que un determinado propietario ejerciese su derecho sin guardar la necesaria armonía con el interés social. Los críticos de la Constitución de 1933 señalaron en algunas ocasiones que la norma carecía de eficacia en razón de no tener sanción. Tampoco hubo leyes posteriores que recogieran para casos específicos el principio del interés social como elemento rector. (...) El art. 924 del nuevo Código Civil pretende salvar la omisión constitucional y establece que cualquier persona o entidad que sufra o esté amenazada de un daño porque otro se excede o abusan en el ejercicio de su derecho, pueda exigir al juez que las cosas se restituyan al estado anterior o que se adopten las medidas del caso, sin perjuicio de la indemnización por los daños irrogados. El ejercicio excesivo o abusivo de la propiedad no necesariamente afecta el interés social. Podría vulnerar tan sólo un interés particular o privado, en cuyo caso el grupo social perjudicado tendría expedito su derecho para exigir que las cosas se repongan al estado anterior o que se adopten las medidas correctivas a juicio del juez, sin perjuicio de la indemnización que corresponda": AVENDAÑO VALDÉZ. "Atributos y caracteres del derecho de propiedad", en VV.AA. Biblioteca para leer el Código Civil, PUCP, Lima 1988, V. I, pp. 102-103.

${ }^{37}$ PÉREZ PÉREZ, Emilio. Propiedad, Comunidad y Finca Registral, CRPME, Madrid 1995, p. 98.

${ }^{38}$ FERNÁNDEZ SESSAREGO, Carlos. Abuso del derecho, Op. Cit., pp. 283-284. 
para dejar sin agua el pozo del vecino ${ }^{39}$. En estos casos, prototípicos, lo que en realidad ocurre es que los límites naturales (o intrínsecos) del derecho subjetivo no están claramente fijados; por lo que el único límite eficaz estará determinado por los criterios objetivos de la buena fe. En tal sentido, se ha observado con razón que si el derecho subjetivo contuviese los límites dentro de los cuales el titular puede actuar legalmente, el abuso del derecho sería una imposibilidad lógica, pero, en la realidad jurídica, tales confines no están precisados, por tanto, la teoría del abuso del derecho sirve para impedir el reconocimiento de situaciones inicuas que se reputan extrañas al contenido mismo dela prerrogativa, pero que ante esa indeterminación de linderos pudieran ser considerados en apariencia como lícitos ${ }^{40}$.

Una institución como el abuso del derecho se origina por necesidades prácticas y por la idea de solidaridad del ordenamiento jurídico; en consecuencia, y al margen de los debates teóricos, lo concreto es que los derechos subjetivos nunca son ilimitados ${ }^{41}$, ni pueden ocasionar daños gratuitos a terceros, bajo pena de convertirse en actos ilícitos. Sin embargo, una teoría tan amplia, e indeterminada se presta ala arbitrariedad judicial, contraria al valor de la seguridad jurídica; por tal razón, desde un principio se vio la necesidad de establecer los elementos configuradores del abuso del derecho ${ }^{42}$. En este punto, se ha optado por el criterio analítico que revela el enfrentamiento entre una regla de derecho, que si bien establece un mandato incondicional por el cual un determinado acto es parte del contenido formal de un derecho subjetivo, sin embargo, resulta prohibidoen mérito de un principio jurídico de amplio alcance.

39 PUIG BRUTAU, José. Introducción al derecho civil, Bosch Casa Editorial, Barcelona 1981, p. 423.

${ }^{40}$ lbíd., p. 424.

${ }^{41}$ Con toda razón dice Antonio Gambaro que la figura del abuso del derecho ha sido utilizado para declarar ilícitos los comportamientos que formalmente están permitidos, pero que devienen en prohibidos luego de un análisis más profundo de la situación, y una vez reconocido que el ejercicio del derecho no ofrece una inmunidad absoluta al titular: Cit. ESPINOZA ESPINOZA, Juan. Ensayos sobre teoría general del Derecho y los derechos de las personas, Editorial Huallaga, Lima 1996, p. 47.

${ }^{42}$ Sobre el particular existe una famosa sentencia del Tribunal Supremo Español, del 14 de febrero de 1944, en el que se desarrollaron los elementos de este instituto (PUIG BRUTAU, Introducción al Derecho Civil,Op. Cit., p. 426): a) Uso del derecho subjetivo de una manera externamente legal; b) Daño a un interés no protegido por una específica prerrogativa legal; c) Carácter inmoral o antisocial del daño, manifestado en forma subjetiva (intención de perjudicar o simplemente la actuación sin un fin serio y legítimo) o en forma objetiva (el daño proviene de exceso o anormalidad en el ejercicio del derecho). No obstante, en el texto principal se explica las razones por las cuales esta doctrina debe considerarse superada. 
Lamentablemente, la jurisprudencia peruana no tiene claro el tema.

Así, recientemente, la Corte Suprema declaró que constituye "abuso del derecho de propiedad", la acción de destrucción de un cerco perimétrico realizada por el presunto propietario de un área en disputa con el vecino, pues si bien como hipotético titular tiene derecho al uso y disfrute, empero, ello no le autoriza ademoler de forma unilateral el cerco, sin que previamente se dilucide el conflicto de límites entre ambas fincas (Casación $\mathrm{N}^{\circ} 747$ 2013, de 06/12/2013, publicada el 31/3/2014 ${ }^{43}$ ). Si entendemos que el abuso de derecho presupone una conducta amparada en una regla que la cubre, pero que se encuentra en contradicción con un principio, entonces debe concluirse que la hipótesis descrita no se ajusta a la figura del abuso del derecho, pues el supuesto propietario despojó de la posesión a su vecino, lo que por sí mismo constituye acto ilícito según el art. 921 del Código Civil, concordante con los arts. 603 y 604 del Código Procesal Civil, de lo cual se deduce que no existe "laguna axiológica", pues el sistema contiene una regla que prohíbe el despojo del poseedor, incluso tratándose del propietario, en cuyo caso, este último, no solo tiene derecho a que se le reponga en la situación anterior, sino también a que se le otorgue una indemnización, que es precisamente la pretensión demandada en el caso. Por tanto, la regla misma ya prevé la ilicitud de la conducta del propietario, por lo que es innecesario acudir al abuso del derecho.

\section{ABUSO DEL DERECHO: PRINCIPIO CONSTITUCIONAL}

\footnotetext{
${ }^{43}$ La sumilla de la ejecutoria -que es una costumbre que empieza a imponerse en las sentencias del Máximo Tribunal- dice: "La recurrente (demandada) no puede alegar que el derribo de los muros levantados por su colindante corresponde al ejercicio regular de un derecho (concretamente de su derecho de propiedad, porque al atribuirse este con anterioridad la propiedad de la zona en conflicto, lo correcto era que la Inmobiliaria procediera a ejercitar las acciones administrativas y legales pertinentes para definir su titularidad sobre el área, y no proceder por la vía de hecho a imponerla, pues ello constituye un abuso de derecho y no su ejercicio regular, considerando que el ejercicio regular de un derecho es aquel que se efectúa respetando los parámetros que son consustanciales a la finalidad económica y social de ese derecho, y que se encuentran inspirados en el principio general de buena fe" (Finalmente, la Corte declaró infundada la casación, por lo que se mantuvo firme la sentencia que concedió indemnización por daño emergente a causa de la demolición del muro).
} 
El abuso del derecho se configura a través del aparente permiso que nace de una regla jurídica, aun cuando, en realidad, la conducta está prohibida por mérito de un principio; sin embargo, tal esquema no es aplicable al conflicto de los derechos constitucionales,pues ello implicaría que se produzca el abuso de un principio sobre el otro, lo que no es posible si entendemos que la Constitución consagra que todos los derechos sean respetados y cumplidos, por tanto, la aplicación de uno sobre el otro no configura abuso alguno.

No obstante, la Constitución Peruana admite el abuso de los derechos constitucionales, y probablemente sea la única en el derecho comparado que regula este punto mediante la escueta fórmula: "La Constitución no ampara el abuso del derecho" (art. 103 in fine), lo que tiene dos consecuencias directas: i) aplicación del abuso en el ejercicio de los derechos constitucionales; ii) aplicación del abuso en el ejercicio de todos los derechos, sin limitarse al ámbito del Derecho civil.

El Tribunal Constitucional se ha pronunciado en pocas oportunidades sobre el abuso del derecho, y en realidad, las más de las veces, lo hace para recordar que la interposición de demandas temerarias, y sin ningún fundamento, es un típico caso de abuso procesal. Por ejemplo, en la STC 00473-2007-PHC/TC, de 16/2/2007, se resolvió el caso de un hábeas corpus planteado para dejar sin efecto resoluciones en materia civil, lo es manifiestamente improcedente, por lo que se: "ha configurado la vulneración del artículo 103 de la Constitución, que proscribe el abuso del derecho. El abuso de los procesos constitucionales no solo constituye grave daño al orden objetivo constitucional sino también a la tutela de los derechos fundamentales de los demás ciudadanos. Esto es así por cuanto al hacer un uso abusivo de los procesos constitucionales se restringe la posibilidad de que este Colegiado pueda resolver la demanda de tutela de quienes legítimamente recurren a este tipo de procesos a fin de que se amparen los derechos fundamentales reconocidos por la Constitución". La misma doctrina sobre abuso procesal, con demandas temerarias, se aprecia en la STC 7624-2005-PHC/TC, FJ 194, STC 2118-2005-PA/TC, FJ $3^{\circ}$ y STC 01045-2008$\mathrm{PHC} / \mathrm{TC}, \mathrm{FJ} 6^{\circ}$.

\footnotetext{
${ }^{44}$ El Tribunal Constitucional declara que un acto puede ser temerario o de mala fe cuando: i) a sabiendas se alegan hechos contrarios a la realidad; ii) se sustraiga, mutile o inutilice alguna parte del expediente; iii) se utilice el proceso con fines ilegales o con propósitos dolosos o fraudulentos; iv) se obstruya la actuación de medios probatorios; v) por cualquier medio se entorpezca reiteradamente el desarrollo del proceso; vi) por razones injustificadas las partes no asisten a la audiencia generando dilación.
} 
Nuevamente el Tribunal considera abusiva la conducta de una parte por su actuación al interior de un proceso (doble pago pretendido por el acreedor), como ocurre en la STC 000037-2012-PA/TC, FJ 68: "la cláusula constitucional que proscribe el abuso del derecho, aplicada al ámbito de los derechos fundamentales, supone la prohibición de desnaturalizar las finalidades u objetivos que sustentan la existencia de cada atributo, facultad o libertad reconocida sobre las personas (...). Los derechos, pues, no pueden utilizarse de una forma ilegítima o abusiva, como ocurre en el presente caso, en que la empresa Telefónica SAA pretenda obtener un doble beneficio por una misma causa, lo que a todos luces resulta inconstitucional"; no obstante, en puridad, tal situación no representa "abuso", puesto que la conducta de cobrar doble es ilícita conforme a una regla de derecho, pues el acreedor solo tiene derecho a exigir la prestación, y no más de eso (art. 1220 CC).

En el ámbito laboral se ha establecido que la contratación temporal para obra o servicio específico exige indicar el hecho concreto que motiva el contrato; por tanto, según la STC 05859-2009-PA/TC, de 22/6/2010, FJ 7: "Que el empleador pretenda desconocer los derechos laborales de sus empleadores por la mera invocación de las reglas de contratación por obra o servicio específico no puede ser un supuesto amparable desde la Constitución. Como se ha argumentado, la licitud de una conducta no se obtiene con el solo hecho de invocar una disposición legal, pues esta no puede utilizarse de forma aislada ni en desconocimiento de los principios constitucionales"; empero, la falta de causa justificada para la contratación temporal no es conducta abusiva, sino ausencia de todo derecho.

En conclusión, la jurisprudencia del Tribunal Constitucional sobre el abuso del derecho es escasa, pero adicionalmente equivocada, pues el acto abusivo presupone la existencia de una regla permisiva, pero en la mayoría de los casos examinados, la regla aplicable, desde su origen, es prohibitiva; por tanto, no puede hablarse de "abuso del derecho" cuando no hay derecho. La única salvedad son algunos casos de ejercicio abusivo del derecho de recurrir a la justicia (abuso procesal).

Entonces, ¿cómo se entiende el abuso del derecho en el ámbito constitucional? La doctrina dice: "puede haber situaciones en las que quepa un uso no justificado -esto es, un abuso- de reglas que constituyan una concreción de derechos fundamentales respecto de los cuales no 
podría hacerse un uso injustificado" 45 . En consecuencia, el esquema planteado es el siguiente: un derecho fundamental se concreta en una regla, pero esta se halla en contraposición a un principio. La fórmula es correcta, pero con la salvedad que el principio contrario al derecho subjetivo es uno de carácter ordenador o transversal de las situaciones jurídicas, como el ejercicio de la buena fe, o la prohibición del fraude, que sirven para delimitar los alcances y límites de las prerrogativas jurídicas. Por el contrario, la aplicación del principio contrario no puede ser un derecho subjetivo constitucional, pues, en tal caso, no hay abuso, sino conflicto, lo que exige ponderación para resolver la situación concreta. Por ejemplo, el periodista que agravia a un personaje público, ¿actúa en ejercicio de la libertad de expresión? Si decimos que sí, entonces es imposible el abuso; y si decimos que no, entonces tampoco hay abuso de un derecho constitucional, que en todo caso pretende expandirse en cuanto sea posible, por tanto, la colisión con el derecho constitucional al honor (principio contrario) se resuelve sobre la base de diversas técnicas jurídicas de adecuación, entre ellas, la ponderación.

\section{ABUSO DEL DERECHO: ¿LÍMITE INTRÍNSECO O EXTRÍNSECO?}

En efecto, los límites intrínsecos son aquellos que se encuentran al interiordel derecho mismo, por tanto, son los presupuestos para que la prerrogativa se ejerza de forma legítima, entre los que se encuentra el abuso del derecho. Por su parte, los límites extrínsecos son aquellos que se encuentran fuera del derecho subjetivo, a extramuros de él ${ }^{46}$, específicamente en el caso de derechos contradictorios, lo que exige la ponderación, con el fin de establecer la prerrogativa preferente en el caso concreto, para lo cual se necesita un juicio estricto de racionalidad.

El abuso del derecho es la hipótesis típica del límite interno que excluye una conducta determinada del ámbito estricto del derecho subjetivo, sea por contravenir su función social, ser contrario a la buena fe u ocasionar exclusivo daño a terceros, lo que se reduce al propio

\footnotetext{
${ }^{45}$ ATIENZA, Manuel y RUIZ MANERO, Juan. Ilícitos atípicos, Op. Cit., pp. 65-66.

46 "Los límites intrínsecos derivan de la propia naturaleza de cada derecho y de su función social. Dentro de ellos suelen diferenciarse a su vez los límites objetivos (que se desprenden de la propia naturaleza, de la misma realidad del derecho) de los subjetivos (que derivan de la actitud del sujeto titular y de la forma de realizar el propio derecho). (...) Los límites extrínsecos derivan de la propia existencia social y de los demás sujetos de derecho que en ella coexisten": FERNÁNDEZ SEGADO, Francisco, "Dogmática de los derechos de la persona ...", Op. Cit., pp. 239-240.
} 
contorno del derecho, que no puede exceder esos contornos. La doctrina del Derecho civil se muestra conforme con esta distinción, pues el abuso del derecho se produce si la conducta "es inmoral o irracional o anormal o antisocial o contrario a la verdad" ${ }^{\prime 4}$; mientras tanto, el abuso es extraño a la "controversia entre dos antagónicos derechos subjetivos" 48 , lo que es hipótesis de colisión, pero no de ejercicio abusivo.

Por tanto, la tesis del abuso del derecho como "ilícito atípico", debe complementarse en el sentido que el principio vulnerado por la regla permisiva es de carácter ordenador o estructural (verbigracia: prohibición del dolo o fraude, ejercicio de buena fe), es decir, la conducta ilícita surge desde el interior mismo o núcleo del derecho, sin que entre en conflicto con otro derecho subjetivo.Por el contrario, cuando la colisión se produzca entre dos prerrogativas o derechos, entonces no hay abuso, pues cada uno de los titulares se encuentra abstractamente dentro del ámbito de su poder, aunque en el caso concreto tendrá que delimitarse los alcances de uno y otro, por ejemplo, mediante la técnica de la ponderación.

El sistema jurídico en su conjunto, según Robert Alexy, se encuentra sujeto a la pretensión de corrección, lo que incluye las reglas, principios y decisiones de los jueces. En este sistema, las disposiciones jurídicas se dividen en reglas y principios, cuyas diferencias van más allá de cuestiones formales o incidentales. Las reglas son normas que ordenan algo en forma definitiva; por ello son normas condicionadas, salvo los casos de reglas categóricas. Por el contrario, los principios son normas que ordenan que algo sea realizado en la mayor medida posible, de acuerdo a las posibilidades fácticas y jurídicas; por ello, los principios se definen como mandatos de optimización.

El Derecho sometido a la pretensión de corrección no se reduce a la norma positiva, al mandato estatal, sino que se integra con la argumentación, esto es, con las buenas razones ordenadas lógicamente para arribar a la mejor solución del caso. Por su parte, los jueces, sobre quienes también se concreta la misma pretensión de corrección, se encuentran especialmente obligados a exponer una argumentación lógica, racional, fundada en la moral

\footnotetext{
${ }^{47}$ D’AMICO, Giovanni. Libertà di scelta del tipo contrattuale e frodeallalegge, GiuffrèEditore, Milán 1993, pp. 105-106, que usa las palabras de Pietro Rescigno.

${ }^{48}$ FERNÁNDEZ SESSAREGO, Carlos, “Abuso del derecho (art. 103 Constitución)”, Op. Cit., p. 701.
} 
crítica, pero también en las normas, precedentes y dogmática, pues el Derecho tiene una base autoritativa, junto con otra ideal.

Una de las situaciones más comprometidas para el juez se presenta cuando debe resolver el conflicto entre dos principios o mandatos de optimización (derechos, valores o bienes constitucionales). Si por definición, los principios tienen naturaleza expansiva para aplicarse en forma generalizada e irradiarse por todo el sistema, entonces se produce un serio problema cuando dos principios se enfrentan, pues obviamente uno deberá limitar al otro. Desde una perspectiva metodológica, en el caso de conflicto entre bienes constitucionales relevantes, no queda otra alternativa que reconocer la expansión de un principio con la subsiguiente exclusión del otro.

En tales casos, el juez deberá motivar esa difícil decisión; pero, ¿cómo hacerlo?, ¿con pura intuición?, ¿con los criterios tradicionales de la interpretación jurídica expuestos desde la pandectística?, o, ¿con otra técnica más acorde a la naturaleza del problema? Alexy propone una argumentación racional crítica, a tono con la pretensión de corrección, basada en el juicio de ponderación, pues, tratándose de principios, en cuanto mandatos de optimización, estos se expanden a todo el sistema jurídico, por lo que la irradiación de uno choca con el otro; por ello, una parte alega un derecho fundamental (por ejemplo: libertad de información), mientras la otra alega otros derechos fundamentales (por ejemplo: intimidad, imagen). En estos casos, la clásica subsunción no es suficiente, pues los principios no son normas definitivas, sino abiertas, dúctiles, en la que difícilmente basta una regla lógica de aplicación; por tanto, se requiere de otro mecanismo racional para arribar a una solución aceptable. En este contexto, se encuentra el principio de proporcionalidad, como medio para resolver los conflictos entre derechos fundamentales ${ }^{49}$, que a su vez se divide en los sub-principios de idoneidad, necesidad y de proporcionalidad en sentido estricto.

${ }^{49}$ En el ejemplo narrado en el texto principal, si bien los periodistas cuentan con amplia libertad de información, siempre que el asunto sea veraz y de interés general, sin embargo, ello no autoriza a vulnerar de modo desproporcionado los derechos a la intimidad y a la imagen propia. Por tanto, el derecho de información queda excluido cuando colisiona, en estas circunstancias, con otros derechos fundamentales. En buena cuenta, la restricción de un principio debe ser idónea para lograr que se cumpla la finalidad de otro principio, necesaria y proporcional. El derecho a la intimidad, aquí, es considerado preferente con relación a la libertad de información, pues para lograr la nota se ha necesitado de introducir una cámara oculta en un ambiente reservado, engañando al interlocutor sobre los fines de la atención médica; con lo cual se defrauda la expectativa legítima de mantener la 
privacidad de la que se goza en ciertos ámbitos. El derecho a la propia imagen es también considerado preferente con relación a la libertad de información, pues se han aprovechado el rostro y la voz del interlocutor, a pesar que no se recabó su autorización; y es más, bajo la técnica utilizada, la idea era obviar el consentimiento del afectado. Por su parte, la STC Español de12/2012, de 30 de enero, FJ 4, señala lo siguiente: "Como hemos señalado reiteradamente, la especial posición que ostenta el derecho a la libertad de información en nuestro Ordenamiento reside en que 'no solo se protege un interés individual sino que su tutela entraña el reconocimiento y garantía de la posibilidad de existencia de una opinión libre, indisolublemente unida al pluralismo político propio del Estado democrático' (STC 68/2008, de 23 de junio, FJ 3). Sin embargo, la protección especial queda sometida a determinados límites tanto inmanentes como externos que este Tribunal ha ido perfilando progresivamente. Entre los límites inmanentes se encuentran los requisitos de veracidad y de interés general o relevancia pública de la información (SSTC 68/2008, FJ 3; y 129/2009, de 1 de junio, FJ 2); en ausencia de los dos mencionados requisitos decae el respaldo constitucional de la libertad de información. Por otro lado, como límites externos el derecho a la información se sitúan los derechos específicamente enunciados en el art. 20.4 CE".

Por tanto, el periodista tiene derecho para informar, e incluso con una especial protección: "De manera que, 'solo tras haber constatado la concurrencia de estas circunstancias resulta posible afirmar que la información de que se trate está especialmente protegida por ser susceptible de encuadrarse dentro del espacio que a una prensa libre debe ser asegurada en un sistema democrático' (STC 29/2009, de 26 de enero, FJ 4)..." (STC Español 12/2012, de 30 de enero, FJ 4). Luego, la Alta Corte agrega que los periodistas tienen la libertad de hacer su trabajo, pues se trata de un derecho prima facie, pero que puede colisionar especialmente con los derechos de la personalidad, tales como la intimidad o la propia imagen, por lo que las técnicas periodísticas no pueden interferir ilegítima o arbitrariamente sin restricciones: "En cuanto a las técnicas periodísticas que puedan utilizarse para la presentación de una información, es cierto, como indica el recurrente en amparo, que el Tribunal Europeo de Derechos Humanos reconoce a los profesionales correspondientes la libertad de elegir los métodos o técnicas que consideren más pertinentes para la transmisión informativa, que debe ser acorde a las exigencias de objetividad y neutralidad (STEDH de 23 de septiembre de 1994, Jersild c. Dinamarca, F 34). Pero asimismo dicho Tribunal ha subrayado que en la elección de los medios referidos, la libertad reconocida a los periodistas no está exenta de límites, y que en ningún caso pueden considerarse legítimas aquellas técnicas que invaden derechos protegidos, ni aquellos métodos que vulneren las exigencias de la ética periodística en cuanto a la solvencia y objetividad del contenido informativo" (STC Español 12/2012, de 30 de enero, FJ 6); en el mismo sentido "el derecho a comunicar y a emitir libremente información veraz no otorga a sus titulares un poder ilimitado sobre cualquier ámbito de la realidad, sino que, al venir reconocido como medio de formación de la opinión pública solamente puede legitimar las intromisiones en otros derechos fundamentales que guarden congruencia con la finalidad expresada, careciendo de efecto legitimador cuando se ejercite de modo desmesurado y exorbitante al fin en atención al cual la Constitución le atribuye especial protección" (STC Español 185/2002, de 14 de octubre, FJ 3), o "en aquellos casos en los que, a pesar de producirse una intromisión en la intimidad, tal intromisión se revela como necesaria para lograr un fin constitucionalmente legítimo, proporcionada para alcanzarlo y se lleve a cabo utilizando los medios necesarios para procurar una mínima afectación del 
Si los principios exigen la máxima realización posible, primero en el ámbito de las posibilidades fácticas, entonces se requiere un análisis de los sub-principios de idoneidad y de necesidad. Por este medio, se trata de impedir ciertas intervenciones sobre los derechos fundamentales que sean evitables sin costo para otros principios, lográndose de esa manera el óptimo de PARETO ${ }^{50}$. Por otro lado, el sub-principio de proporcionalidad en sentido estricto se refiere a la máxima realización en el ámbito de las posibilidades jurídicas.

Por ejemplo: una periodista se hace pasar por clienta de una esteticista y naturista, que la atiende en su gabinete profesional, sin embargo, la periodista graba la sesión con cámara oculta y luego se presenta un reportaje televisivo con tales imágenes, aduciendo que la citada esteticista ejerce la actividad sin contar con el título habilitante, lo que constituye un grave problema de salud pública. Luego, la esteticista plantea demanda contra dos medios televisivos, y, finalmente, el Tribunal Supremo la estima parcialmente pues considera que se ha producido una ilegítima intromisión sobre el derecho a la intimidad e imagen personal de la afectada, en cuanto el material difundido y el derecho a la información no justifica la intrusión; además, que era innecesario el método de cámara oculta para exponer los problemas de ejercicio sin titulación, y que, por último, no se requirió el consentimiento de la

ámbito garantizado por este derecho, no podrá considerarse ilegítima" (STC Español 156/2001, de 2 de julio, FJ 4).

50 “El principio de idoneidad excluye la aplicación de medios que, como mínimo, perjudiquen la realización de un principio sin favorecer al menos uno de los principios u objetivos a cuya consecución deben servir. Cuando un medio $\mathrm{M}$ que se crea para fomentar la realización del principio $\mathrm{P} 1$ no es apto para ello, e incluso perjudica posiblemente la realización del principio P2, entonces, no resultan costes para P1 ni para P2 si se deja caer M. Así, pues, en atención a las perspectivas reales, P1 y P2 pueden realizarse conjuntamente en un nivel más alto si se abandona M. Esto demuestra que el principio de idoneidad no es otra cosa que una manifestación de la idea del óptimo de Pareto: una posición puede ser mejorada sin que resulten perjuicios para otra. Lo mismo vale para el principio de necesidad, el cual postula que, de dos medios que acaso favorezcan igual de bien a P1, se elige aquel que afecte menos intensamente a P2. Si existiera un medio con menor intensidad de injerencia e igualmente idóneo, entonces, puede ser mejorada una posición sin que se ocasionen costes para la otra. La aplicabilidad del principio de necesidad presupone, sin embargo, que no haya un tercer principio P3 que sea afectado negativamente por el medio cuyo uso interferiría en P2 con menor intensidad. En esa coyuntura el caso ya no puede ser resuelto más con base en razonamientos que se apoyen en la idea del óptimo de Pareto. Cuando no se puedan evitar costes o sacrificios, será necesaria una ponderación": ALEXY, Robert. "Derechos Fundamentales: Ponderación y Racionalidad", en CARBONELL, Miguel y GARCíA JARAMILLO, Leonardo (Eds.). EI canon neoconstitucional, Editorial Trotta, Madrid 2010, pp. 111-112. 
actora para emitir su imagen ${ }^{51}$.Los dos medios televisivos recurren en amparo ante el Tribunal Constitucional español, alegando que el derecho a la información veraz tiene prevalencia frente a los derechos individuales de la persona, en especial los derechos a la intimidad personal y propia imagen. La STC 12/2012, de 30 de enero de 2012 deniega los amparos, pues considera que la decisión del Tribunal Supremo es correcta. Este es un típico caso de conflicto entre dos principios constitucionales, que requiere la ponderación, por lo que corresponde hacer un análisis más detallado.

Así pues, por el sub-principio de idoneidad, la medida sirve para lograr los propósitos del principio A, pero ello implica, simultáneamente, interferir o restringir otro principio B. Sin embargo, si la medida afecta el principio B, pero en nada beneficia el principio A, entonces la conclusión es que tal medio solo produce perjuicio, y su eliminación en nada afectaría a uno u otro principio $^{52}$.La existencia de idoneidad en la medida interventora o restrictiva no prejuzga si esta es necesaria y proporcional, pues se trata de requisitos distintos y sucesivos.

\footnotetext{
51 "El Tribunal Supremo no discute que el reportaje fuera plenamente veraz ni tampoco el interés general en informar de los riesgos del intrusismo profesional, pero estima que tales datos no eran suficientes para resolver el conflicto entre el derecho a la intimidad y la libertad de información. El Tribunal destaca que del reportaje no resulta con suficiente claridad que la actora ejerciera sin título la condición de fisioterapeuta; tampoco se aclara por qué fue ella la persona elegida para dar un ejemplo público de una práctica inadmisible, sin que la condena anterior bastara a tal efecto. Considera igualmente que el material obtenido y difundido públicamente carecía de la relevancia necesaria para justificar el sacrificio de un derecho fundamental imprescindible en la vida de relación, y que el método utilizado para consumar la primera fase de la intromisión -la llamada cámara oculta- no era imprescindible para descubrir la verdad de lo que acontecía en la consulta de la actora, habiendo bastado a tal efecto con realizar entrevistas a sus clientes. El Tribunal Supremo estima asimismo el motivo de casación basado en la infracción del derecho a la propia imagen (art. 18.1 CE), en cuanto que la demandante en casación fue privada, tanto en el momento de la grabación como en el de la emisión televisiva, del derecho a decidir, para consentirla o impedirla, sobre la reproducción de la representación de su aspecto físico determinante de una plena identificación. Por otro lado, en cuanto que el reportaje se centró en la persona de la demandante, incluso emitiendo su imagen durante las manifestaciones de los invitados, la convirtió en elemento fundamental de la información, no cabe entender que se grabara y publicara una imagen meramente accesoria de la información a los efectos del apartado segundo del art. 8.2 c) de la Ley Orgánica 1/1982": STC Español 12/2012, de 30 de enero, antecedentes, acápite e.

${ }^{52}$ En el ejemplo, la periodista grabó a través del mecanismo de cámara escondida una sesión con una esteticista en su gabinete profesional, con el fin de preparar un reportaje respecto a los servicios médicos sin titulación profesional, lo que representa un grave peligro para la salud pública. Esta medida busca obtener información que pueda ser relevante para el conocimiento del gran público y, con ello, sensibilizar a la población respecto de un tema que merece ser objeto de deliberación y debate dentro del ámbito político. En consecuencia, la grabación con cámara oculta tiene como finalidad asegurar el derecho a la información veraz; por lo que claramente se trata de un fin legítimo y serio, pero ello obviamente afecta otros derechos fundamentales.
} 
Por el sub-principio de necesidad, debe tenerse en cuenta que la medida que sirve a la consecución de los fines del principio A, también restringe en forma simultánea el principio $\mathrm{B}$, por lo que debe evaluarse si el propósito buscado con A puede lograrse sin B o con una 
medida que restrinja en menor medida o grado a $\mathrm{B}^{53}$. En tal caso, la medida original no es necesaria y puede ser sustituida con ventaja para todos ${ }^{54}$.

${ }^{53}$ La ponderación no se puede hacer sin argumentación racional. Sin embargo, algunos autores han criticado el excesivo desarrollo analítico del juicio de ponderación, que se traduce en fórmulas matemáticas. Así, por ejemplo, se dice que: "O sea, Alexy nos muestra cuáles son los lugares, los tópicos, a los que hay que acudir para resolver conflictos entre derechos o entre bienes (entre $\mathrm{X}$ e $\mathrm{Y}$ ): la medida $\mathrm{M}$ es idónea para alcanzar $\mathrm{X}$; no hay otra medida $\mathrm{M}^{\prime}$ que permita satisfacer $\mathrm{X}$ sin lesionar $\mathrm{Y}$; en las circunstancias del caso (o bien, en abstracto) $X$ pesa más -es más importante- que $Y$; etc. Pero nada más. Quiero decir que uno se puede muy bien ahorrar el esfuerzo contable y tampoco tiene por qué pensar, por ejemplo, que la necesidad de la medida juega solo en relación con las posibilidades de tipo fáctico y no a propósito de lo que Alexy llama ponderación en sentido estricto, y que se refiere a las posibilidades normativas, etc. Mi sugerencia es, por tanto, la de no seguir a Alexy en su excesivo afán sistematizador, sino hacer un uso más pragmático y, por así decirlo, oportunista de esas ideas": ATIENZA, Manuel. "A vueltas con la ponderación", en Íd. y GARCÍA AMADO, Juan Antonio. Un debate sobre la ponderación, Palestra Editores, Lima 2012, p. 22.

${ }^{54}$ En el caso, la pregunta sería si la cámara oculta puede ser reemplazada por un mecanismo menos invasivo para lograr el mismo fin de información, con análoga eficacia, pero sin afectar derechos fundamentales. La respuesta no es complicada: la información del medio televisivo quería llamar la atención sobre los peligros a la salud por obra de personas que engañan a los consumidores con títulos o especialidades que no tienen. Sin embargo, tal finalidad no requería el medio invasivo de una cámara oculta, pues hubiera bastado, por ejemplo, con difundir el nombre de la persona o personas que ejercen actividades médicas con carácter informal, tal vez haciendo una llamada para concertar una cita o enfocando la fachada del local. Nótese que en cualquiera de esas hipótesis, el fin se cumple en la misma magnitud, pero no se afecta en lo absoluto los derechos fundamentales. Por tanto, la conclusión es que la medida resulta innecesaria; y para ello no basta invocar que la información es veraz o de interés general; pues ello no justifica la intromisión extraordinaria en la intimidad e imagen. En efecto, la intimidad protege el entorno personal o círculo íntimo del sujeto, así como las actividades que generan la legítima expectativa de reserva, por lo que se encuentran excluidas las miradas del público, pues de esa manera se cuenta con el soporte necesario para la autonomía individual y el resguardo de los fines o necesidades personales. Por su parte, el derecho a la imagen prohíbe la difusión del aspecto visual de una persona, con lo cual se logra el aseguramiento de la paz y tranquilidad de la persona. Pues bien, la introducción de una cámara, sin autorización de la otra parte, en un ambiente cerrado, constituye una interferencia que no resulta necesaria para la finalidad pretendida, pues en realidad existen múltiples medidas para presentar el mismo reportaje, con igual eficacia e intensidad, pero sin vulnerar derechos de terceros. La veracidad de la información no justifica que se utilice cualquier mecanismo de información periodística, cuando ello implica vulneración de los derechos ajenos; pues resulta obvio que el reportaje televisivo pudo presentarse sin tal afectación. Por otro lado, el interés general tampoco permite un medio invasivo de derechos fundamentales, salvo cuando tal acción sea necesaria, pero en este caso queda claro que no había tal exigencia.

Sobre el derecho a la intimidad, la jurisprudencia constitucional se ha pronunciado en el siguiente sentido: "La intimidad protegida por el art. 18.1 CE no se reduce necesariamente a la que se desarrolla en un ámbito doméstico o privado. El Tribunal Europeo de Derechos Humanos ha señalado que sería muy restrictivo limitar la noción de vida privada protegida por el art. 8.1 del Convenio 
Por su parte, el sub-principio de proporcionalidad en sentido estricto se refiere a la optimización relativa a las posibilidades jurídicas, cuyo ámbito propio es la ponderación, y se presenta cuando juegan las reglas de desarrollo de los principios, o cuando se tienen dos principios en sentido contrario ${ }^{55}$. En este último ámbito, hay tres pasos para tomar la decisión que busque la corrección ${ }^{56}$ :

i. Definir el grado de afectación de uno de los principios.

ii. Definir la importancia de la satisfacción del principio que juega en sentido contrario.

europeo para la protección de los derechos humanos y de las libertades fundamentales a un 'círculo íntimo' en el que el individuo puede conducir su vida personal a su manera y excluir plenamente el mundo exterior no incluido en este círculo. No puede desconocerse que también en otros ámbitos, y en particular en el relacionado con el trabajo o la profesión, se desarrollan relaciones interpersonales, vínculos o actuaciones que pueden constituir manifestaciones de la vida privada": STC Español 12/2012, de 30 de enero, FJ 5.

Sobre el derecho a la imagen: "Ya habíamos señalado en nuestra STC 117/1994, FJ 3, que 'el derecho a la propia imagen, reconocido por el art. 18.1 de la Constitución al par de los de honor y la intimidad personal, forma parte de los derechos de la personalidad y como tal garantiza el ámbito de libertad de una persona respecto de sus atributos más característicos, propios e inmediatos como son la imagen física, la voz o el nombre, cualidades definitorias del ser propio y atribuidas como posesión inherente e irreductible a toda persona": STC Español 12/2012, de 30 de enero, FJ 5, que continúa en los siguientes términos: "La sentencia impugnada (del Tribunal Supremo) valora correctamente los datos que concurren en la presente situación, y concluye con la negación de la pretendida prevalencia de la libertad de información. Conclusión constitucionalmente adecuada, no solo porque el método utilizado para obtener la captación intrusiva -la llamada cámara oculta- en absoluto fuese necesaria ni adecuada para el objetivo de la averiguación de la actividad desarrollada, para lo que hubiera bastado con realizar entrevistas a sus clientes, sino, sobre todo, y en todo caso, porque, tuviese o no relevancia pública lo investigado por el periodista, lo que está constitucionalmente prohibido es justamente la utilización del método mismo (cámara oculta) por las razones que antes hemos expuesto" (FJ 7).

55 “La ponderación es objeto del tercer sub-principio del principio de proporcionalidad, es decir, del principio de proporcionalidad en sentido estricto. Este principio expresa lo que significa la optimización en relación con las perspectivas jurídicas. Es idéntico a una regla que se puede denominar 'ley de la ponderación', que reza como sigue: 'cuanto mayor sea el grado de incumplimiento o menoscabo de un principio, tanto mayor debe ser la satisfacción del otro'. La ley de la ponderación expresa que la optimización en relación a un principio en conflicto no se basa en otro, sino en la ponderación": Ibíd., p. 112.

${ }^{56}$ ALEXY, Robert. "La fórmula del peso", en Íd. Teoría de la argumentación jurídica, anexo, Palestra Editores, Lima 2007, pp. 458-460. 
iii. Definir si la importancia de la satisfacción del principio contrario justifica la restricción o la no satisfacción del otro ${ }^{57}$.

En este punto cabe recordar la noción de los "derechos prima facie", bien conocidos en la teoría y filosofía del derecho, cuya característica es que otorgan una prerrogativa, pero que puede ser superada por otro derecho en una circunstancia particular ${ }^{58}$. Su antítesis son los "derechos absolutos", esto es, los que no ceden en ninguna circunstancia y son prevalentes en todos los casos. Bajo esta perspectiva, todos los principios, salvo el de dignidad, tienen la condición de prima facie, pues en determinada situación pueden ser derrotados por otro principio, por lo que dejan de aplicarse en el caso concreto.En el ejemplo, tanto la libertad de información, como los derechos a la intimidad y a la propia imagen, son prima facie, pues uno puede terminar limitado por los otros, y viceversa ${ }^{59}$.En suma, los principios como mandatos de optimización dentro de las posibilidades fácticas y jurídicas, entran en colisión con otros principios que también pretenden lo mismo, por cuyo mérito, el conflicto entre ambos determina que uno sea excluido, y el otro, no; por tanto, los principios disponen algo, pero prima facie, pues las razones del principio opuesto lo pueden descartar ${ }^{60}$.

${ }^{57}$ En el caso concreto, el grado de afectación del derecho a la intimidad e imagen es grave, pues la periodista grabó la sesión con la esteticista con una cámara oculta, creando ella misma la noticia, para lo cual invadió la esfera íntima de una consulta y captó la imagen de una persona sin su autorización, lo cual implica que se trata de una intromisión de máxima magnitud en los derechos fundamentales de la persona. Por el contrario, la satisfacción del principio contrario es mínima, sino inexistente, pues la libertad de información nada gana con un reportaje que tiene una connotación básicamente sensacionalista, en cuanto difunde una grabación oculta, que obviamente despierta el interés de la audiencia televisiva con fines coyunturales e incidentales de simple curiosidad o morbosidad, pero que en nada apoya ni mejora el nivel de la información. En consecuencia, la satisfacción de la libertad de información, que prácticamente nada gana con la cámara oculta, obviamente no justifica la restricción de los derechos constitucionales afectados a la intimidad e imagen.

58 "De este modo, los derechos pueden sobrevivir a conflictos entre ellos, aun cuando uno tenga que ceder ante el otro: el conflicto es un conflicto entre dos derechos que importan y no se resuelve eliminando uno de ellos, sino solo tomando una decisión sobre cuál de ellos importa más en la situación planteada": MENDONCA, Daniel. Los derechos en juego. Conflicto y balance de derechos, Editorial Tecnos, Madrid 2003, pp. 53-54.

59 “Así, por ejemplo, el derecho a la información no es un derecho absoluto, sino simplemente un derecho prima facie, porque en algunas situaciones es superado por algún otro derecho, tal como el derecho a la intimidad": Ibíd., p. 53.

60 “Los principios ordenan que algo debe ser realizado en la mayor medida posible, teniendo en cuenta las posibilidades jurídicas y fácticas. Por lo tanto, no contienen mandatos definitivos, sino solo prima facie. Que un principio valga para un caso no significa que lo que el principio exige para este caso tenga validez como 
El conflicto entre principios diferentes es una hipótesis típica de limitación extrínseca del derecho, pues la restricción proviene desde fuera.

\section{CONCLUSIONES}

El abuso del derecho, desde el aspecto ideológico, pone en entredicho dos ideas básicas de la modernidad: el individualismo, atacado por la solidaridad, y la seguridad normativa de la codificación, reemplazada por conceptos generales susceptibles de interpretación judicial.

Por su parte, desde el aspecto estructural, el tránsito de la permitido a lo prohibido conlleva que la conducta sea calificada como "ilícito atípico", pues si bien la conducta se encuentra formalmente cubierta por una norma permisiva, sin embargo, en el caso concreto, la regla se encuentra en contradicción con algún principio jurídico ordenador o estructural.

El abuso del derecho es un límite intrínseco, es decir, se encuentran al interiordel derecho mismo, por lo quese trata de uno de los presupuestos para que la prerrogativa se ejerza en forma legítima.Por su parte, los límites extrínsecos son aquellos que se encuentran fuera del derecho, a extramuros de él, específicamente el choque o colisión dederechos subjetivos, que en apariencia cubren la situación concreta, una para permitirla, y la otra para prohibirla.

resultado definitivo. Los principios presentan razones que pueden ser desplazadas por otras razones opuestas. El principio no determina cómo ha de resolverse la relación entre una razón y su opuesta. Por ello, los principios carecen de contenido de determinación con respecto a los principios contrapuestos y las posibilidades fácticas": ALEXY, Robert. Teoría de los derechos fundamentales, CEPC, Madrid 2007, traducción de Carlos Bernal Pulido, pp. 80-81. 